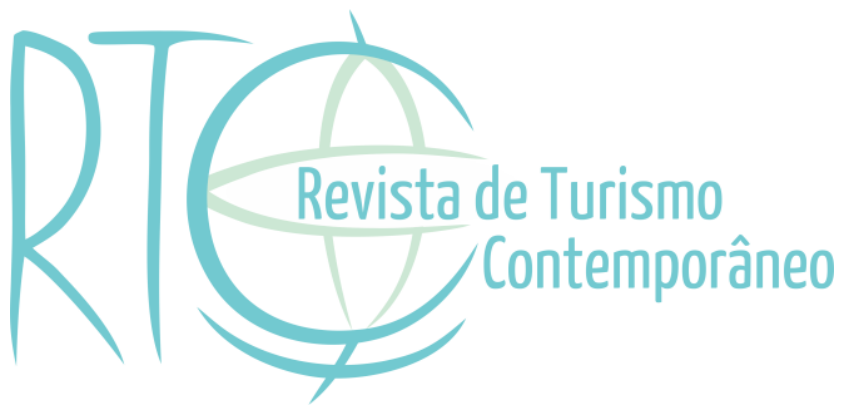

\title{
Hospitalidade no Buraco da Catita: música e comensalidade como atrativos turísticos em Natal/RN, Brasil
}

\section{Hospitality in Buraco da Catita: music and commensality as tourist attraction in NataL/RN, Brazil}

\section{Cristiane Kateline de Andrade Oliveira}

Bacharel em Turismo pela Universidade Federal do Rio Grande do Norte - UFRN, Natal/RN, Brasil

E-mail: katelineoliveira@gmail.com

\section{Silvânia Melo da Cunha}

Graduanda em Administração pela Universidade Federal do Rio Grande do Norte - UFRN, Natal/RN, Brasil

E-mail: silvaniamelo0508@gmail.com

\section{Amanda Almeida Gomes Dantas}

Mestre em Saúde Coletiva pela Universidade Federal do Rio Grande do Norte - UFRN, Natal/RN, Brasil

E-mail: almmeidaamanda@gmail.com

\section{Maria Bernadete Cavalcante}

Bacharel em Turismo pela Universidade Federal do Rio Grande do Norte - UFRN, Natal/RN, Brasil

E-mail: bernacavalcante@gmail.com

\section{Sueli Aparecida Moreira}

Professora Adjunto IV do Curso de Hotelaria da Universidade Federal Rural do Rio de Janeiro - UFRRJ, Seropédica/RJ, Brasil

E-mail: suelimoreira@yahoo.com.br 


\section{RESUMO}

Considerando o crescente interesse turístico pela experiência de inserção na cultura local, realizou-se o presente estudo com o objetivo de caracterizar a hospitalidade do Bar e Espaço Cultural Buraco da Catita. A hospitalidade foi apreendida através da comensalidade e musicalidade enquanto atrativos para o bairro da Ribeira, localizado em Natal-RN. Foram coletados depoimentos dos proprietários e dos usuários em relação ao Bar Buraco da Catita; perfil dos usuários do bar; serviços aos comensais e hospitalidade. As informações foram obtidas através de entrevista com enquete semiestruturada contendo 09 perguntas, aplicada aos 32 usuários do Buraco da Catita. Os resultados evidenciaram que o bar possui grande potencial turístico, pois associa 03 importantes aspectos: a gastronomia, a música e a edificação histórica. A gastronomia e a música favorecem a comensalidade, assegurando a boa hospitalidade. Estratégias de divulgação do Bar e da Ribeira poderão fomentar o turismo gastronômico e de experiência da cultura local.

Palavras-chave: Turismo Cultural. Comensalidade. Hospitalidade. Buraco da Catita. Ribeira.

\section{ABSTRACT}

Considering the growing touristic interest in the immersive experience of local culture, the present study was carried out with the objective of characterizing the hospitality of the Buraco da Catita Cultural Space and Bar. The hospitality was assessed through comensality and musicality as attractions of the Ribeira neighborhood, located in Natal, RN. Testimonials were collected from the owners and consumers in relation to the Buraco da Catita Bar; the profile of the bar's consumers; the hospitality and services available to diners. The information was obtained through scripted interviews, comprised of semi-structured forms containing 09 questions, and applied to 32 patrons of Buraco da Catita. The results highlighted the great touristic potential of the bar, as it encompasses 03 important attributes: gastronomy, music and its historic building. The gastronomy and music favor the commensality, thus assuring good hospitality. Strategies to promote the Bar and the Ribeira neighborhood can foster the gastronomic tourism and the experience of the local culture.

Keywords: Cultural Tourism. Commensality. Hospitality. Buraco da Catita. Ribeira. 


\section{INTRODUÇÃO}

O bairro da Ribeira é um dos mais antigos de Natal, um lugar repleto de praças exuberantes e paisagem singular às margens do Rio Potengi. A Ribeira recebeu esse nome porque chegou a ser confundida com uma campina alagada, explicou Câmara Cascudo (1999). Contudo, o povoamento da Ribeira deu-se de maneira lenta e foi iniciado nas atuais ruas Doutor Barata, Chile e General Glicério, durante o século XVIII.

Em 1904 houve uma seca que deixou a terra enxuta e fez surgir poças de água salobra, cujo aterramento permitiu Herculano Gomes fazer a jardinagem no local. Então, naquela época instalaram-se: comércios, armarinhos, farmácias, alfaiatarias, clubes de dança e um cinema no padrão da época (Fernandes, 2015). Com o tempo o bairro passou a abrigar diversas repartições públicas, bares, museus, teatro, igrejas e uma centena magazines.

A Ribeira abriga boa parte do Centro histórico da capital potiguar. O bairro integra o Corredor Cultural de Natal cujo trajeto permite caminhar pelo seu rico conglomerado de prédios históricos. Em relação à hospitalidade no período noturno, Muneiro e Freire (2012), destaca importância dos restaurantes e bares, boates e casas de shows para ampliar e diversificar o público na Ribeira.

O reconhecimento da Ribeira permite compreender antropologicamente a formação da sociedade natalense, cuja segregação sócio espacial pode ser emblematicamente endereçada à Ribeira em seus primórdios. É conveniente revisitar a história para suscitar o imenso potencial turístico da mesma. Nesse sentido, a Secretaria do Meio Ambiente e do Urbanismo SEMURB aponta que:

\footnotetext{
O bairro teve seu período áureo nos anos 40, quando era núcleo do comércio de Natal, atraindo as mais importantes figuras da elite natalense e o povo em geral com grande movimentação no final das tardes. Visando tirar Ribeira do marasmo que a atinge após o horário comercial, fazendo reviver os velhos tempos, boêmios e intelectuais natalenses procuram achar uma saída para a revitalização do bairro. Em 1993, o Seminário Ribeira Velha de Guerra discutiu propostas para o bairro. Uma dessas foi o Projeto VIVA A RIBEIRA (SEMURB, 2007, p. 7).
}

A Ribeira tem sido contemplada pelo calendário de eventos da Prefeitura de Natal, com destaque para a Virada Cultural de Natal; Festival Literário; Cine Natal; Salão de Artes Visuais. Em 2017 e 2018, a Ribeira sediou assertivamente o primeiro e o segundo Natal Fest Gourmet, festival gastronômico com pratos regionais, concurso de gastronomia, exposição de arte e shows musicais, com a capacidade para atender duas mil pessoas por dia. A experiência gastronômica de cardápio regional motiva o turismo em destinos com culinária típica bem estabelecida. A gastronomia potiguar, assim como dos demais estados brasileiros, recebeu 
influências dos povos indígenas, portugueses, africanos e de outros imigrantes. Câmara Cascudo, na obra História da Alimentação no Brasil, relata como as etnias influenciaram nos costumes alimentares e convoca ao "respeito de herança dos mantimentos de tradição" (Cascudo, 2004, p. 14).

Câmara Cascudo também descreve os hábitos dos potiguares quanto à comensalidade e alimentação e explica que o almoço era servido às nove, o jantar às três e a ceia ao escurecer, pois na época não era de fácil acesso à energia elétrica para os bairros. O açúcar refinado era caro, então, frequentemente usava-se a rapadura para adoçar os alimentos. As receitas mais produzidas pelas donas de casa eram: pão de ló, bolo de ovos, doces secos, comidas de milho, doces em calda, pastéis de nata ou de carne, suspiros, sequilhos, alfenins. Juntando com os ingredientes locais, usavam goma de mandioca e faziam: raivas, bolos de goma, rosca doce. Havia pouco consumo de bebida alcoólica no Brasil. O mais ingerido era uma cachaça como aperitivo, um copo de vinho durante um jantar importante e água durante a refeição. Tais aspectos demonstram que "a cozinha potiguar é um caldeirão criado pela herança de várias culturas" (Cascudo, 1999, p. 70).

Durante a viagem, a apreciação da gastronomia regional em boa companhia representa uma experiência única de inserção na cultura local. Até porque, cotidianamente não se dispõe de tempo hábil para se desfrutar dos convívios à mesa. De acordo com Moreira (2010), a convivência à mesa ou comensalidade faz parte de um padrão alimentar que vem sendo modificado em decorrência da globalização. Segundo a autora, esse fenômeno aliado ao movimento de fast food trouxe profundas modificações na organização social, individualizando as refeições. Em busca da economia de tempo aceitou-se o consumo de uma alimentação previsível, em detrimento da cozinha tradicional, cuja elaboração requer a espera, valoriza o consumo de produtos da terra e o prazer da comensalidade.

A gastronomia assegura uma experiência única de interação com a cultura local, exercendo papel fundamental ao turismo, principalmente tratando-se da hospitalidade e restauração (Bezerra \& Moreira, 2017). Durante a estadia, a restauração cumpre o papel fundamental de suprir os aspectos práticos vitais de fome e saciedade, mas também proporciona convívio e sociabilidade durante as refeições. No contexto turístico, Schlüter (2003) ressalta que as cozinhas regionais representam um importante atrativo para se conhecer a identidade cultural do lugar visitado, enquanto Fagliari (2005) percebe a gastronomia como uma estratégia para atrair o público, funcionando como chamariz para o fomento de outras atrações. Portanto, o planejamento adequado com engajamento dos setores 
público e privado para restaurantes e bares, considerando os atributos da identidade regional, enaltece a cultura, trazendo benefícios econômicos e sociais.

Sob perspectiva hospitaleira, o Bar reúne música popular brasileira, artistas locais e cozinha regional em meio aos casarões antigos no bairro da Ribeira. O Buraco da Catita cultiva a memória de um prédio histórico onde a hospitalidade pode promover o sentimento de identificação com a cultura local. A partir da ideia de memória proposta por Bosi (2004), como intermediário cultural entre gerações, que permite revisitar a biografia dos fundadores da Ribeira. Então, com a justificativa de reconhecer e divulgar a importância históricocultural do bairro da Ribeira, sob perspectivas de desenvolvimento turístico para o local, realizou-se o presente estudo com o objetivo de caracterizar a hospitalidade do Bar através da comensalidade, da camaradagem à mesa e da musicalidade do chorinho com artistas locais.

\section{METODOLOGIA}

Foi realizado estudo transversal de desenho misto através de entrevista com enquete semi estruturada. Foram obtidos depoimentos dos proprietários e da gerente do Bar e Espaço Cultural Buraco da Catita. O depoimento permite realizar um "corte" na memória, a fim de estudar um espaço específico, segundo Meksenas (2002). Considerou-se que memória segundo Bosi (2004) se enraíza no concreto, no espaço, gesto, imagem e objeto. A história liga apenas às continuidades temporais, às evoluções e às relações entre as coisas, afirma a mesma. Para avaliar a parte prática dos serviços, aplicou-se uma enquete semi estruturada com os usuários. De acordo com Meksenas (2002), a enquete é uma abordagem quantitativa da pesquisa empírica que lida categórica e objetivamente com os dados, com objetivos definidos para obter a opinião dos sujeitos. As abordagens se complementam para melhor compreensão da hospitalidade daquele lugar.

Foram realizadas entrevistas de forma individual entre os dias 23 de Abril e 15 de maio de 2015, cujos sujeitos foram selecionados por livre demanda durante o período. Foram envolvidos 32 clientes do Bar que preencheram individualmente a enquete sobre o perfil da clientela do bar, atratividade comensal e hospitalidade. As entrevistas complementares com os proprietários foram conduzidas fora do horário de expediente.

Em relação ao expediente, o bar funciona normalmente dois dias por semana, sextafeira das $18 \mathrm{~h}$ às $01 \mathrm{~h}$ e sábado das $18 \mathrm{~h}$ às $02 \mathrm{~h}$. Porém, excepcionalmente, em algumas semanas, ele é aberto na quinta-feira das $18 \mathrm{~h}$ às $01 \mathrm{~h}$. Para a entrada no local é cobrada uma taxa de ingresso individual de $\mathrm{R} \$ 20,00$ (vinte reais) e de $\mathrm{R} \$ 60,00$ (sessenta reais) para mesa. 
Em obediência à resolução CNS/MS 466/2012 antes da entrevista era lido o Termo de Consentimento Livre e Esclarecido - TCLE, em respeito aos aspectos éticos, os nomes dos entrevistados foram substituídos por nomes fictícios, para garantir o sigilo e confidencialidade.

A entrevista com os proprietários Marcelo Tinoco e Marcelo Lima contou com um roteiro igualmente aplicado com a gerente Jurema Silva. Dessa forma foram obtidos depoimentos sobre a história do bar, o horário de funcionamento, como são feitas as escolhas das atrações musicais, perfil de clientes do bar, elaboração do cardápio e atratividades. As respostas foram organizadas em uma planilha simples para facilitar a analise e categorização dos resultados.

O perfil do cliente foi caracterizado com variáveis sobre gênero, idade e naturalidade ou proveniência para identificar a presença de turistas. O instrumento apreendeu também os meios de divulgação, bem como a freqüência ou assiduidade da clientela; percepção do cliente sobre a localização e o atendimento para avaliar a hospitalidade.

\section{REFERENCIAL TEÓRICO}

\subsection{Globalização: alimentação e cultura}

Cultura pode ser interpretada como a junção de variados conhecimentos e práticas populares ou sociais sugere Andrade (2000). Montanari (2008) a define como uma mistura entre tradição e a inovação. Em outra visão, Cuche (2002) aponta que o termo também tem sido empregado com diferentes significados em substituição a outras palavras como "mentalidade", "espírito", "tradição" e "ideologia".

Para Edgar Morin (1997), a cultura é organizada/organizadora pelo veículo cognitivo da linguagem, a partir do capital coletivo dos conhecimentos adquiridos, das competências aprendidas, das experiências vividas, da memória histórica, das crenças míticas de uma sociedade. Nesse sentido, a cultura detém o saber acumulado em memória social.

Pela perspectiva do turismo histórico, Barreto (2006) acrescenta que a cultura é um importante atrativo, pois impulsiona e motiva o deslocamento das pessoas em busca de apreciar e conhecer as tradições de outra sociedade, como visitas aos museus, memoriais e monumentos que compõem o patrimônio histórico-cultural do lugar.

Os patrimônios são os guardiões da cultura e da memória social. "A palavra Patrimônio vem do latim patrimonium, e está associada a bens familiares, herança e posses, 
ou seja, o legado de um povo" (Tavares, Dantas, \& Nóbrega, 2014, p. 3). Por sua vez, é possível classificar os patrimônios dividindo-os em material e imaterial.

O patrimônio cultural material, segundo o Instituto do Patrimônio Histórico e Artístico Nacional - IPHAN (2014), é composto por um conjunto de bens culturais classificados em quatro categorias de tombo. O tombamento é o mais antigo instrumento de proteção em utilização pelo IPHAN, tendo sido instituído pelo Decreto-Lei no 25 , de 1937 (DL 25/37), e proíbe a destruição de bens culturais tombados, colocando-os sob vigilância do Instituto. Para ser tombado, um bem passa por um processo administrativo, até ser inscrito em, pelo menos um dos quatro Livros do Tombo instituídos pelo Decreto: Livro do Tombo Arqueológico, Etnográfico e Paisagístico; Livro do Tombo Histórico; Livro do Tombo das Belas Artes; e Livro do Tombo das Artes Aplicadas (Brasil, 1937).

Dentro destas categorias encontram-se os bens imóveis "como as cidades históricas, sítios arqueológicos e paisagísticos e bens individuais" ou móveis "como coleções arqueológicas, acervos museológicos, documentais, bibliográficos, arquivísticos, videográficos, fotográficos e cinematográficos" (IPHAN, 2014). Já conceituando patrimônio cultural imaterial, segundo a Organização das Nações Unidas para a Educação, a Ciência e a Cultura - UNESCO (2006):

As práticas, representações, expressões, conhecimentos e técnicas - com os instrumentos, objetos, artefatos e lugares culturais que lhes são associados - que as comunidades, os grupos e, em alguns casos os indivíduos, reconhecem como parte integrante de seu patrimônio cultural (UNESCO, 2006, p. 3).

A Ribeira concentra boa parte do Patrimônio Cultural de Natal, portanto o planejamento turístico deve considerar aspectos históricos do passado atentando-se ao modo de vida contemporâneo. No atual contexto, a preservação das tradições pode ser ameaçada pela Globalização. Contreras-Hernández (2005) durante revisão definiu globalização como:

Um amplo processo de transformações sociais, incluindo o crescimento do comércio, dos investimentos, viagens, redes de informática, no qual as numerosas forças entrecruzadas entre si fazem com que as fronteiras de todo tipo e de todos os níveis (...) é um processo progressivo de homogeneização e de perda da diversidade (Contreras-Hernández, 2005, p. 129).

A culinária é uma das mais importantes expressões culturais da identidade de um povo. Contudo, pode sofrer adaptações em consequência da globalização, conforme costumes e preferências pessoais. Seja por mudança nos ingredientes, no modo de preparo ou no modo de servir. Assim, novos pratos surgem e descaracterizam os originais, conforme expôs Cascudo (2004): 
[...] as recepções com salgadinhos, as bandejas circulantes, as comidas nos restaurantes automáticos, o cachorro-quente, o sanduíche frio, a desculpa de não ter tempo para comer, aplicando-o noutras tarefas inferiores, o disfarce decorativo mutilando a integridade sápida, as maquinais self-services, a banalidade policolor dos drugstores, são fatores adversos à boa e venerada tradição cozinheira (Cascudo, 2004, p. 361).

A criação e execução na produção dos alimentos envolvem objetos, técnicas e costumes que foram sendo construídos e adquiridos com o tempo. A caracterização da identidade através da alimentação de um local faz parte do patrimônio imaterial do lugar. $\mathrm{Na}$ receita está contida a história que prevalece na memória.

\subsection{Gastronomia e turismo}

O comportamento alimentar caracteriza-se pelo modo de obtenção dos ingredientes, modo de preparo e suas combinações que reiteram a cultura de um povo. Prova disso é o fato de etimologia da palavra potiguar deter em sua definição atrelada ao comedores de camarão. A gastronomia é tão estabelecida que encontra-se no âmago da palavra potiguar. Elementos que fazem parte da culinária potiguar revelam informações sobre a organização social do povo, as influências recebidas e o secreto ritual de se alimentar. Desse modo, no que se refere à gastronomia Castro e Santos (2012) expõem:

A gastronomia é a ciência que compreende a culinária, as bebidas, os ingredientes
(especiarias, temperos, farinhas, queijos, etc.) usados no preparo das refeições, os
utensílios que são demandados na elaboração dos alimentos e todas as
peculiaridades culturais ou não, a ela integradas. Contudo, não se deve confundir
gastronomia com a culinária (arte puramente da confecção dos alimentos), nem com
a nutrição e dietética (que examinam a alimentação no ponto de vista da saúde e
medicina) (Castro \& Santos, 2012, p. 167).

O Turismo Gastronômico é o deslocamento motivado pela gastronomia típica de localidades e regiões (Brasil, 2010). Bares e restaurantes são oportunidades ideais para que anfitriões potiguares compartilhem com turistas a experiência da gastronômica local. A gastronomia articula a atividade turística com a oferta de serviços de alimentação e permite estabelecer uma experiência direta nos costumes locais. A comida atrai e complementa outros produtos da oferta turística local, associando-se ao turismo cultural. De acordo com Defert (1987), para grande parte dos visitantes, o ato de comer bem durante a viagem equipara-se, em importância, ao conforto do transporte e às comodidades do alojamento. Polàcek (1986) por sua vez, relata que ao viajar, uma das principais motivações de um turista é o desejo de escapar da rotina diária em relação ao ambiente, atividade e alimentação do cotidiano. Em revisão, o autor encontrou que, na Alemanha em 1985, 43\% dos entrevistados preferiam 
"comer especialidades locais" e 35\% viajariam para "comer bem". Em Natal, na zona norte concluiu-se que "todos os elementos que precedem o ritual do encontro são identificados na mesa do bar, de maneira que essa relação acaba por influenciar a sensação de pertencimento local” (Lima, Cunha, \& Moreira, 2019, p. 114).

\subsection{Hospitalidade: comensalidade e música}

Uma das características positivas de um estabelecimento é a do bem acolher os clientes. E o ato de ser gentil gratuitamente vai além de oferecer um serviço eficiente, é poder ser eficaz. Essas características pertencem ao conceito de hospitalidade, que segundo Grinover (2007) vem de influências anglo-saxônicas e refere-se aos aspectos de hospedagem, alimentação, entretenimento e lazer, entendido como:

[...] uma dimensão da cultura constituída pela vivência lúdica de manifestações culturais no tempo/espaço conquistado pelo sujeito ou grupo social, estabelecendo relações dialéticas com as necessidades, os deveres e as obrigações, [...] (Gomes, 2004, p. 125).

A hospitalidade está estreitamente ligada à maneira como nos alimentamos, respeitando crenças e valores sociais. Segundo Castelli (2010), o encontro à mesa é uma oportunidade de praticar a hospitalidade. Franco (2001) reafirma dizendo que a hospitalidade surge através do prazer de estar à mesa, depois de todo o ritual de preparar os pratos, arrumar o local onde será servido, pôr a mesa, servir e compartilhar com os convivas. Nesse contexto, Castelli (2010) recorda sobre o prazer no ato de comer, um dos aspectos que nos distingue do reino animal. A comensalidade ou rito de beber e comer em conjunto é um rito de agregação (Gennep, 1977, p. 43).

Nessa perspectiva, a comensalidade pode ser considerada uma das maiores expressões para avaliar hospitalidade. Por isso, ao adentrar o Buraco da Catita reitera-se atmosfera hospitaleira propícia para se socializar, compartilhar petiscos e bebidas, descontraindo-se com os atrativos musicais e a boa camaradagem dos serviços de mesa.

Cascudo (2004) afirma que nenhuma atividade será tão permanente na história da humanidade como a alimentação e que a sociologia da alimentação fundamenta-se no ato social. Sobre fatores negativos, o referido autor também menciona a perda do hábito da refeição realizada em casa. Ou seja, a crescente substituição de pratos tradicionais pelas comidas rápidas prontas para consumo ou para microondas. 
A seguir, as figuras 1a, 1b e 1c, documentadas no Buraco da Catita, mostram que o cardápio é composto de pratos em forma de petiscos, característicos dos bares, porém ambos sofreram adaptações com ingredientes típicos da cultura potiguar:

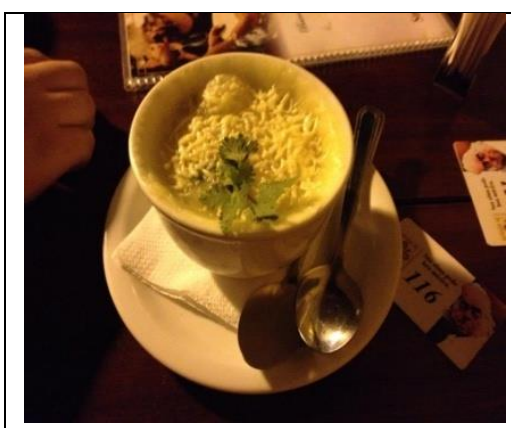

Figura 1a - Petisco adaptado com ingredientes típicos Escondidinho

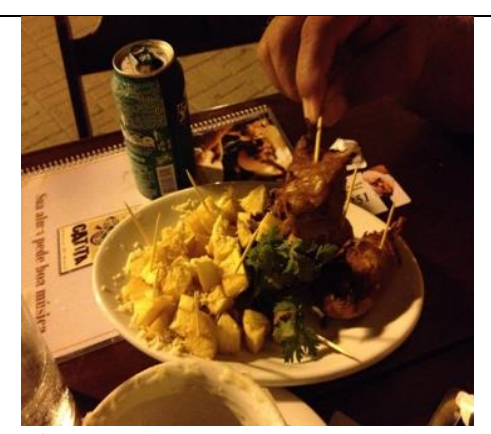

Figura 1 b - Petisco adaptado com ingredientes típicos Macaxeira Frita

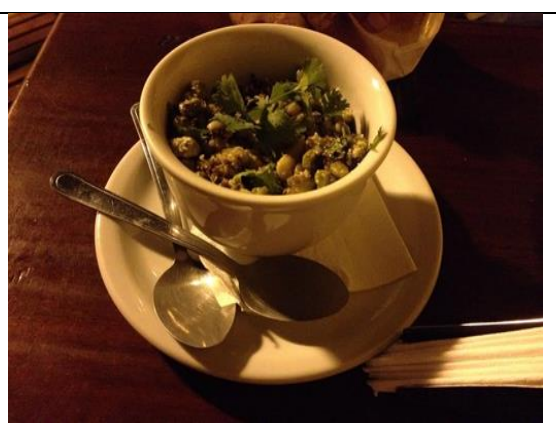

Figura 1c - Petisco adaptado com ingredientes típicos - Paçoca e Feijão Verde

Fonte: Pesquisa Departamento de Turismo - DETUR/UFRN, 2015.

Ao se pensar nas cozinhas regionais, é possível considerar que os elementos culturais por sua vez são parte da memória social. Então, quando é apresentado no cardápio porções e petiscos com ingredientes regionais, como o "escondidinho de macaxeira com carne de sol", "espeto de queijo de coalho e macaxeira frita" ou a "paçoca" (feijões-verdes com carne de sol frita e triturada com farofa e coentro) há uma forma de salvaguardar a cultura alimentar do lugar.

De acordo com o Ministério do Turismo (2010) em 2008 foi realizada pesquisa da EMBRATUR em parceria com a UNESCO, onde se buscou identificar o perfil e o comportamento do turista internacional que veio conhecer o Brasil. Os resultados da referida pesquisa apontam que a musicalidade, as danças e a hospitalidade foram destacadas como as características mais expressivas (60\%), seguido das manifestações populares (47\%), artesanato e gastronomia (30\%).

É possível analisar, através desse Espaço, semanalmente bem frequentado pelo público local, visitantes e turistas, os elementos do turismo cultural, sobretudo, conhecer os artistas locais na área da música, os quais ocupam, em apresentações noturnas, o palco do espaço, além de viver a comensalidade e revisitar uma memória histórica, através da arquitetura secular ainda presente no bairro. Nesse caso, Bosi (2004), explica que a memória nos reconquista na medida em que é um trabalho sobre o tempo, abarcando também esses tempos marginais e perdidos na vertigem mercantil.

Choro (chorinho) samba, forró, pagode, baião é o "mix" de ritmos que o Espaço Cultural Buraco da Catita oferece para um público heterogêneo. O chorinho, por sua vez, traz 
para o público mais jovem, que hoje disputa com uma geração três vezes mais velha, o espaço e o privilégio de poder conhecer um ritmo considerado como a primeira música urbana tipicamente brasileira. E no Buraco da Catita aglutina músicos de todas as vertentes.

Os bares e restaurantes fazem parte da rotina dos moradores de Natal. Os bares da Ribeira e dedutivamente, dos que visitam a cidade também. Nesta acepção do item cotidiano, alguns estabelecimentos são adotados como oferta técnica, tornando mais intensa a transformação deles em atrativo turístico. É preciso buscar minuciosamente algo particular do estabelecimento que chame a atenção do turista.

Além da comida, diversos outros fatores podem tornar um estabelecimento de alimentação atrativo. Uma pessoa famosa, história interessante, serviço diferente ou alguma outra peculiaridade (Fagliari, 2005). A pluralidade de funções em um restaurante ou bar é outro artifício utilizado para atrair turistas e cativar os moradores locais. Para decidir que tipo de alimento será utilizado, deve se levar em consideração as expectativas dos possíveis clientes. Assim, o Buraco da Catita usa ingredientes tipicamente potiguares como o camarão, o feijão-verde, o queijo de coalho e outros que estão relacionados ao cotidiano potiguar. Barreto e Senra (2001) ao analisarem a realidade gastronômica no Brasil e sua importância para o turismo observaram que algumas iguarias gastronômicas chegam a transcender sua origem geográfica, tornando-se peças emblemáticas de propaganda de seus estados.

O setor de alimentos e bebidas apresenta também suas fragilidades, como as sazonalidades do turismo que afetam na escassez de clientes em períodos específicos do ano, o grande número de estabelecimentos que aumenta a concorrência, a falta de mão de obra qualificada (chef formado) bem como a informalidade de alguns locais.

\subsection{Origem do espaço cultural Buraco da Catita}

Discorrer acerca da origem do Buraco da Catita - com o uso de estilos musicais que fazem referência ao local com compositores e intérpretes Potiguares como forma de aquecer a memória social e preservar o contexto do bairro da Ribeira - é necessariamente, resgatar também a origem do bairro da Ribeira.

Assim, a Ribeira, também conhecida como Cidade Baixa, nasceu banhada pelas águas do rio Potengi e está geograficamente localizada na zona leste de Natal, a capital do Estado. Por volta de 1838, poucas ruas ainda compunham o cenário do bairro, porém destaca-se que das poucas ruas existentes, todas elas já se destinavam ao comércio e serviços, evidenciando a "vocação" deste bairro para esta atividade na capital potiguar (Nascimento, 2015). 
As atividades comerciais no bairro incentivaram uma série de melhorias em sua infraestrutura ao longo do tempo. Nascimento (2015) destaca que em 1850, prédios de pedra e cal e muitos armazéns começam a surgir no bairro, dinamizando cada vez mais essa atividade. Segundo o autor, foi, no entanto, em 1870, que a Ribeira ganhou grande destaque, quando o então presidente da província, Pedro de Barros Cavalcante de Albuquerque transfere a sede do governo local para um sobrado na Rua do Comércio, fato que trouxe importância vital a esse bairro e deu um grande impulso ao seu crescimento, vindo a se tornar neste período o principal mais importante e movimentado bairro da cidade e palco dos grandes acontecimentos que se realizavam na cidade de Natal.

De acordo com a revisão da literatura realizada por Nascimento (2015), é mencionada pelo autor a importância que a Ribeira teve para o projeto urbano de Natal. Segundo registros, as mesmas ruas estreitas dos dias atuais e com pouco movimento da Ribeira, como a Chile, a Frei Miguelinho e a Doutor Barata, não tem ideia do que elas representaram nas décadas de 30 e 40 do século passado. O comércio era atrativo e a sede do governo conferia uma atmosfera de poder à localidade. As avenidas Duque de Caxias e Tavares de Lyra, largas e arborizadas, já traziam a nova tendência urbanística da cidade. As praças José da Penha e Augusto Severo complementavam o roteiro de charme. Nesse contexto, o surgimento do bairro da Ribeira e suas caracterizações evidenciam sua importância no contexto histórico e urbanístico da capital potiguar.

Do ponto de vista da hospitalidade boemia, a Ribeira ou Cidade Baixa como era conhecida, se contrapondo à Cidade Alta e à boemia de luxo do Cabaré Maria Boa, era famosa pelo Beco da Quarentena com uma identidade mais popular e até depreciativa. Enquanto no bairro da Cidade Alta, no esplendoroso cabaré, primava-se pela higiene, saúde e privacidade, no ostracismo delegado ao Beco da Quarentena reinava o extremo oposto, cenário descrito por Lima, Dalcin e Barros (2012):

Os padrões de comportamento relegados à fina flor da sociedade, a locais de
refinamento conjunto com os prazeres sexuais, o paraíso masculino no qual se
discutia os mais variados temas, palco de reuniões e subterfúgio para encontro com
belas damas de vida fácil, prontas e satisfeitas ao entregar-se em troca de favores
comerciais. Em detrimento de um local insalubre, perseguido por sua má fama,
fantasmas de uma peste jamais esquecida, jogatinas, traições, brigas, mulheres
capazes de tudo por um pedaço de pão e criminalidade, o aroma da pobreza em seu
mais alto apogeu (Lima, Dalcin, \& Barros, 2012, p. 9).

Analisar os bares na sociedade contemporânea requer compreender a complexidade de vislumbrá-los não apenas como estabelecimentos de serviço de refeições, mas também como espaços que podem ser realizadas as práticas de lazer. E também favorável aos 
relacionamentos interpessoais, pois é parte importante no desempenho da atividade turística. “O boteco agregou, absorveu influências variadas [...] e também se tornou ponto de referência e socialização" (Miranda \& Cornelli, 2004, p. 98).

As informações apresentadas a seguir mostram a história, o funcionamento, a criação do cardápio e a percepção dos proprietários e da gerente do Buraco da Catita quanto aos clientes. Para conhecer a história do Bar e Espaço Cultural e perceber as características de hospitalidade (comensalidade e música) foi realizada uma entrevista com os proprietários do Boteco. Dessa maneira, o Marcelo Tinoco falou a respeito da criação do bar e da história e Marcelo Lima evidenciou a escolha das atrações culturais e do cardápio. A entrevista também foi realizada com a gerente, que falou sobre o perfil do cliente.

Segundo Tinoco que é arquiteto, músico e professor da UFRN, o Espaço Cultural Buraco da Catita é uma Associação sem fins lucrativos e a trajetória do Bar insere-se no movimento pela revitalização do Centro Histórico de Natal, que foi espelhada na de outros centros culturais do Brasil.

Em curso desde o início dos anos 90. Foi à época do Plano Diretor de 1994, que, dentre seus objetivos, buscava compatibilizar desenvolvimento urbano com proteção de valores históricos, culturais e ambientais da cidade de Natal (Tinoco, 2015).

Através do projeto "Fachadas da Rua Chile" foram recuperadas em média, 45 imóveis. Consolidando-o como um local para manifestações culturais da cidade até hoje.

Se de um lado o Poder Público buscava valorizar os atributos urbano-ambientais da Ribeira, de outro, arquitetos, jornalistas, artistas, músicos e intelectuais mobilizavam-se em torno do resgate dos valores artísticos e culturais do centro histórico (Tinoco, 2015).

Marcelo Tinoco uniu-se a um grupo de amigos, participou da fundação das bandas: Banda Independente da Ribeira (uma orquestra de frevo), Grupo Ribeira de Pau e Corda, (tocavam marchas). Em 2007, o "Ribeira de Pau e Corda" fez parte da agenda do carnaval da prefeitura de Natal, ao fim do carnaval parte do grupo passaram a se encontrar semanalmente no Beco da Lama (Cidade Alta), e tocavam chorinho e samba.

Foram esses encontros que resultaram na criação do grupo "Catita Choro e Gafieira". Foi uma forma de homenagear o compositor e o autor de um choro chamado "Catita", chamado K-Ximbinho. E nas apresentações, o número do público foi consideravelmente crescendo e a estrutura não comportava essas pessoas. Por questão de segurança, saíram do centro da cidade e foram para a Ribeira: 
Assim, em abril de 2008, nascia o "Buraco da Catita", localizado na esquina da Rua Câmara Cascudo com a Travessa José Alexandre Garcia, em plena Zona de Preservação Histórica do bairro da Ribeira. Dia 23 de abril de 2008, dia nacional do choro e aniversário de Pixinguinha, adotando como padrinho da casa, o médico e bandolinista João Juvanklin (Tinoco, 2015).

De acordo com a gerente Jurema da Silva, o bar funciona após o horário comercial, ou seja, a partir da sexta-feira a partir das $18 \mathrm{~h}$ até $01 \mathrm{~h}$ e aos Sábados das $18 \mathrm{~h}$ às $02 \mathrm{~h}$. Com exceções na quinta-feira, quando tem algum projeto cultural.

Quanto às atrações do bar, elas são escolhidas pelo proprietário e também administrador do local Marcelo Lima, de acordo com o dia e disponibilidade da banda. Ficou pré-determinado que nas sextas-feiras haveria como ritmo musical o chorinho, a gafieira e a MPB (Música popular brasileira) e no sábado o samba.

Marcelo Tinoco complementa dizendo que, desde quando o Espaço Cultural Buraco da Catita instalou-se na Ribeira "as manifestações culturais sempre ocorreram em uma relação direta do edifício com o espaço público, através de apresentações musicais no meio da rua”. Com a popularização dos eventos, ultrapassaram-se os limites da calçada e passou a ter apresentações na rua e fechar a via pública (uma travessa que fica de frente).

$\mathrm{O}$ bar teve que sofrer algumas alterações ao longo dos anos. Em relação à adequação do edifício preservaram-se os aspectos que evidenciam sua caracterização histórica, de acordo com princípios estabelecidos para reabilitação de edificações inscritas na Poligonal de Tombamento do Centro Histórico de Natal, assim explica Marcelo Tinoco.

De acordo com um representante adjunto da SEMURB (2007), em entrevista ao portal eletrônico Tribuna do Norte, quando a calçada é larga, é possível ocupar parte do espaço com mesas, mas é necessário deixar um espaço livre de no mínimo 1,20 metro de largura para o livre trânsito de pessoas (SEMURB, 2007).

As figuras 4 e 5 a seguir, demonstram como são dispostas as mesas e cadeiras e uma noite com apresentação musical:

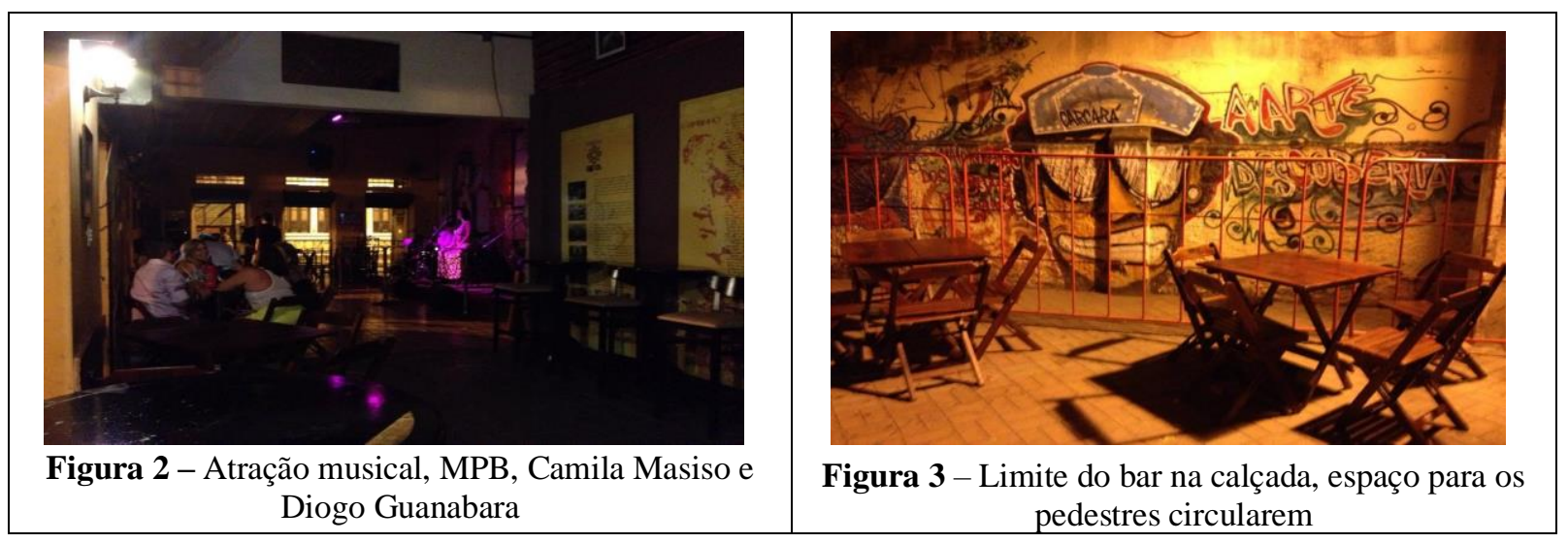

Fonte: Pesquisa DETUR/UFRN, 2015. 
Nesse sentido, eles utilizaram um projeto que ainda não havia sido posto em prática, com o nome de "Becos e Travessas". Foi desenvolvido pela Prefeitura de Natal com a proposta de incentivar o uso das travessas localizadas no interior do sítio histórico da Ribeira pelos pedestres.

Quando questionada, a gerente Jurema diz perceber um público muito variado no bar e que os turistas que vão ao local são avulsos, nunca em grupos levados por agências. Explica que "eles chegam à tarde, pedem para fotografar e acabam voltando à noite. Alguns vêm indicados por pessoas que moram na cidade e outros pela banda que vai se apresentar no dia".

Quanto à escolha do cardápio e saída deles, Marcelo Lima disse que todo o cardápio foi criado por uma chef de cozinha, que após elaborá-lo apenas passou as técnicas de produção, montagem e forma de servir para os funcionários e quando necessário faz ajustes e/ou mudanças no cardápio. Ela utilizou ingredientes da cozinha potiguar por ser de fácil acesso e por pertencer a um bar com contexto histórico, com o objetivo de passar para os clientes quais são os alimentos locais. A gerente que vivencia o dia a dia do bar explica que os pratos mais pedidos são os petiscos como escondidinho de macaxeira e carne de sol, pastel de carne de sol e frango a passarinho com macaxeira frita. O Espaço Cultural Buraco da Catita desempenha hoje um papel indutor no processo de Revitalização da Ribeira e do Turismo Cultural.

\section{RESULTADOS E DISCUSSÃO}

A hospitalidade do Bar e Espaço Cultural Buraco da Catita localizado no bairro da Ribeira em Natal-RN considerado um dos primeiros bairros da capital potiguar onde a riqueza histórica e a hospitalidade através da música e comensalidade podem movimentar a atividade em turismo cultural.

\subsection{Perfil dos clientes}

Foram incluídos no estudo 32 participantes. Destes, 59,4\% eram do sexo masculino, encontravam-se na faixa etária acima dos 30 anos $(53,1 \%)$ e eram residentes de Natal e Grande Natal $(90,6 \%)$ (Tabela 1). 
Tabela 1 - Análise descritiva das variáveis: sexo, idade e naturalidade da clientela que frequenta o Buraco da Catita.

\begin{tabular}{lcc}
\multicolumn{3}{c}{ Natal, Rio Grande do Norte, Brasil, 2015. $n=32$} \\
\hline Variável & N & $\%$ \\
\hline Sexo & 13 & 40,6 \\
Feminino & 19 & 59,4 \\
Masculino & & \\
Idade & 15 & 46,9 \\
Até 30 anos & 17 & 53,1 \\
Acima de 30 anos & & \\
Naturalidade & 29 & 90,6 \\
Natal e Grande Natal & 3 & 9,4 \\
Outras Regiões & 32 & 100,0 \\
Total &
\end{tabular}

Fonte: Pesquisa DETUR/UFRN, 2015.

A presença masculina no bar é historicamente explicada por Miranda e Cornelli (2004), segundo os autores:

A bebida alcoólica sempre foi procurada pela população masculina operária, na saída das fábricas e nos momentos de descanso. [...] O espaço de convívio dos homens era o botequim, ou boteco, como é chamado em São Paulo. O termo bar é mais recente de influências norte-americano, difundindo após a $2^{\mathrm{a}}$ guerra mundial, principalmente por influência do cinema (Miranda \& Cornelli, 2004, p. 99).

Ainda que a Ribeira guarde sua história de hospitalidade boemia, seu passado pode explicar a frequência masculina predominante. Entre as movimentações na Ribeira, está o Beco da Quarentena, um famoso local de promiscuidade no qual os frequentadores buscavam prazeres baratos e encontravam-se quartos escuros e abafados onde se hospedam meretrizes que outrora viveram seu apogeu em prostíbulos mais luxuosos e terminavam seus dias no Beco da Quarentena, estigmatizando a Ribeira para o turismo de frequência masculina (Lima, Dalcin, \& Barros, 2012):

Embora o Beco da Quarentena fosse considerado local de obscuridade - no livro Breviário da Cidade do Natal, o escritor Manoel Onofre Júnior finaliza o capítulo A Zona: 'O velho beco, com seu 'claro mistério', continua maldito. As pessoas decentes o evitam, até mesmo durante o dia, como se o vissem ainda empestado" -, também foi palco de inspiração para os poetas da cidade. O poeta Civone Medeiros Tonig escreveu versos sensuais em seu poema Bilhete na Ribeira: "Quero comer teu riso /Não tema! /É instinto! /Insisto! /Se antena! /Na madruga... Quero te comer no Beco da Quarentena" (Lima, Dalcin, \& Barros, 2012, p. 8).

Em estudo de Lima, Dalcin e Barros (2016) sobre a gastronomia do Mercado Público da Redinha como atrativo turístico, em outro bairro da cidade de Natal, corrobora o resultado da superioridade numérica de pessoas do sexo masculino em estabelecimentos dessa natureza, uma vez que, os homens que frequentam o Mercado, o utilizam para praticar a comensalidade 
em forma de bar, com os amigos para beber, comer e conversar. Na pesquisa o número de frequentadores correspondia a $65 \%$ do total da amostra.

$\mathrm{Na}$ pesquisa realizada por Silva (2013), em que a autora analisou a qualidade de serviços prestados em empreendimentos existentes na praia da Redinha Velha (Natal-RN) foi relatado uma prevalência do público masculino, em que "os frequentadores mais assíduos do destino turístico eram em sua maioria do gênero masculino", salientado que o percentual de entrevistados desse gênero foi de $76 \%$, equivalendo a 34 entrevistados, enquanto as mulheres correspondiam a 24\% (11 mulheres) de um universo de 45 clientes entrevistados.

\subsection{Caracterização do bar}

Dos 32 participantes desse estudo 65,6\% obtiveram informação sobre o lugar por meio da indicação de outras pessoas, enquanto apenas 34,4\% tomaram conhecimento pelas mídias sociais (Tabela 2). Conforme Cafferky (1999 como citado em Bentivegna, 2002, p. 8), "mais de $80 \%$ das pessoas seguem as recomendações de um familiar, amigo ou um profissional ao adquirirem um produto ou serviço".

Miranda (2008) afirma que o marketing trabalha a ideia do convencimento. No turismo, as técnicas de marketing estão sendo consideradas fundamentais para construir ferramentas que conquistem o consumidor. É uma forma de levar o consumidor até o produto.

Os autores Schiffman e Kanuk (1995) dizem que tornar público os produtos e serviços através de canais interpessoais é também conhecido como propaganda ou marketing informal e pode ocorrer pessoalmente ou por intermédio de uma ferramenta da tecnologia que seja usada para a comunicação, como um diálogo por telefone. E as mídias sociais se enquadram no perfil de divulgação informal. 
Tabela 2 - Análise descritiva da caracterização do Bar da Catita sob a ótica da clientela. Natal, Rio Grande do Norte, Brasil, 2015.

\begin{tabular}{lcc}
\multicolumn{1}{c}{$n=32$} & $\mathbf{N}$ & $\mathbf{\%}$ \\
\hline Variável & & \\
\hline Conhecimento sobre o Lugar & 11 & 34,4 \\
Mídias Sociais & 21 & 65,6 \\
Indicação de Pessoas & & \\
Atratividade & 20 & 62,5 \\
Programação Musical & 21 & 65,1 \\
Gastronomia & 15 & 46,9 \\
Lazer & & \\
Frequência de Visita & 16 & 50,0 \\
Primeira vez/Uma vez & 5 & 15,6 \\
Uma vez no mês & 11 & 34,4 \\
Uma vez ao ano & & \\
Localização & 26 & 81,2 \\
Boa & 5 & 15,6 \\
Regular & 1 & 3,2 \\
Ruim & 32 & 100,0 \\
Total
\end{tabular}

Fonte: Pesquisa DETUR/UFRN, 2015.

Na Tabela 2 pode ser observado que das atrações existentes do local analisado, a mais mencionada para atrair a clientela foi a gastronomia $(65,1 \%)$. Tal aspecto permite consagrar a própria cultural do local, pois, como afirma Castro e Santos (2012, p. 157) "a gastronomia se relaciona com o turismo cultural para ser difundida e consolidada como identidade de um local uma vez que, por meio da alimentação, se conhece os costumes dos residentes de uma região e também suas histórias de vida".

Assim, a cultura, a gastronomia e o turismo são elementos que andam juntos, uma vez que os viajantes têm a necessidade de consumir e descobrir novos sabores. Os turistas vêm em busca de destinos contrastantes aos seus costumes cotidianos (Lima, Dalcin, \& Barros, 2016).

O Turismo gastronômico no RN envaidece-se pela sua rica identidade cultural, em parte explicada pelo contraste da cultura sertaneja, onde ocorre a criação de animais de pequeno porte como cabras e galinhas de Angola, em relação à gastronomia à base de camarão e frutos do mar no litoral. Condições naturais diversas produziram riquezas e tradições culinárias distintas e saborosas (Lima, Dalcin, \& Barros, 2016, p. 51).

Ainda como demonstrado na Tabela 2, 50\% dos entrevistados informaram que estavam no estabelecimento pela primeira vez e $81,2 \%$ afirmaram que a localização deste estabelecimento era boa, verificada também através das respostas dos clientes. Embora o percentual alto de pessoas que aprovam a localização do estabelecimento, a maioria aponta como é pequeno o fluxo de pessoas que circulam a noite no bairro da Ribeira.

Dessa forma, pode-se verificar melhor a partir das respostas a seguir: Podemos verificar melhor através das respostas dos clientes: "Boa, sem movimento nas proximidades, 
mas com segurança no local” (Sabrina); "Boa, apesar de não ser um bairro movimentado, ele tem seu charme" (Maurício); "Regular, por ser isolado da movimentação" (João); "Ruim, eu sozinha não viria ao bar" (Cristina). Tais depoimentos podem ser exemplificados através das figuras abaixo:

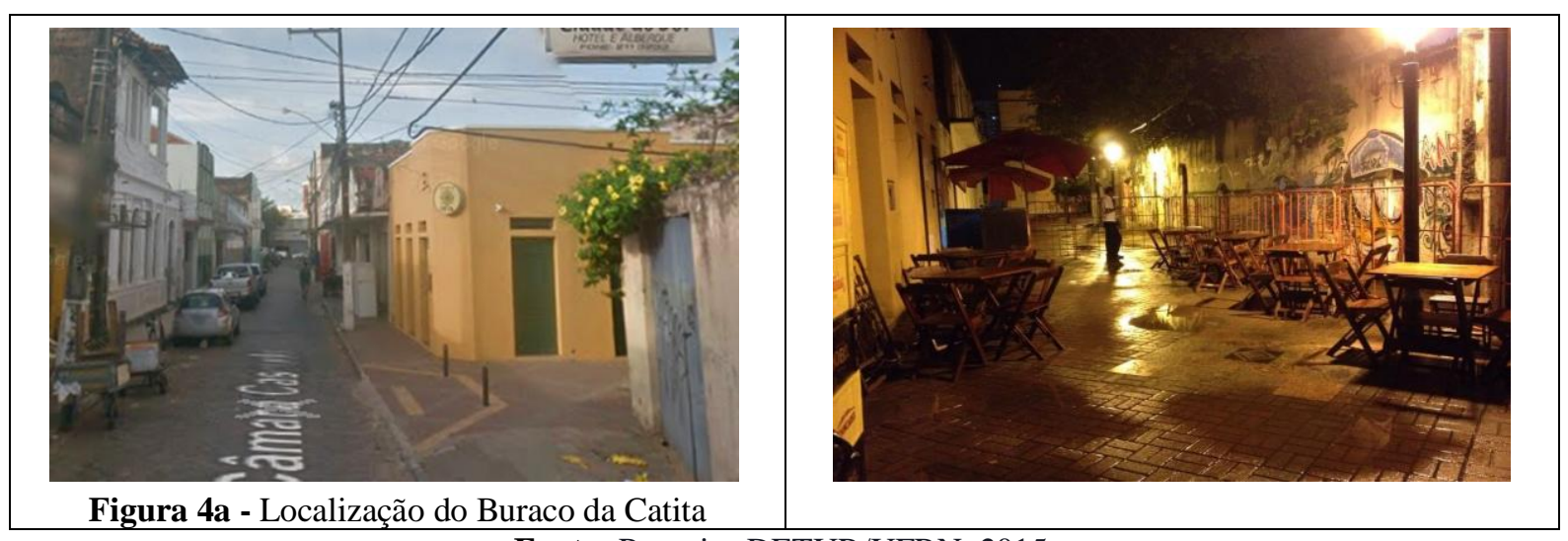

Fonte: Pesquisa DETUR/UFRN, 2015.

Provavelmente, quem vai ao bar percebe quais são as características do bairro, já que os clientes em sua maioria são de Natal. O bairro da Ribeira fez em sua estrutura o reaproveitamento de algumas edificações. Assim como o Buraco da Catita, possui outros prédios de função comercial em estruturas históricas. Logo, sabendo que o horário comercial é das $8 \mathrm{~h}$ às $18 \mathrm{~h}$, e que o expediente do bar é das $18 \mathrm{~h}$ às $02 \mathrm{~h}$, percebe-se que o fluxo de pessoas é reduzido.

Em observação no Boteco, constatou-se que os clientes que chegaram às 20hrs, permaneceram no bar em média 4 (quatro) horas. A propaganda através das mídias sociais pode atrair o turismo noturno.

\subsection{Hospitalidade}

A abordagem da temática da hospitalidade passa, necessariamente, pelo estudo das condutas alimentares (Castelli, 2010). Para Lima, Cunha e Moreira (2019) a comensalidade é considerada o ápice do processo de hospitalidade, através da qual se reconhece a convivência, o respeito e a tolerância. "Petiscar" com amigos e ouvir música para descontrair em meio a um ambiente histórico favorece a hospitalidade.

Os dados a seguir demonstram a percepção dos clientes sobre a qualidade do atendimento e do serviço de mesa. Para Lima, Dalcin e Barros (2016) o serviço gastronômico de boa qualidade é responsável pela fidelização e indicação do destino a outros usuários. 
Sobre o serviço de mesa, a maioria dos clientes respondeu que acredita que o Espaço cultural tem um bom serviço de mesa: "Sim, tem funcionários a todo o momento efetuando esses serviços" (Patrícia). A maioria dos clientes que escolheu a opção "Ótimo e Bom”. A qualidade do atendimento garante a boa hospitalidade, conforme apontando por Silva (2013, p. 24) "a hospitalidade é considerada um fator importante para qualquer estabelecimento que faça parte do trade turístico, pois é a partir da receptividade que garantirá a fidelidade e retorno, através de uma boa avaliação por parte do consumidor".

Quando interrogados sobre o atendimento dos funcionários, 65,6\% acreditam ter recebido um ótimo ou bom atendimento. Os 7 clientes ou 21,9\% disseram ter recebido um atendimento regular. E por fim, 12,5\% tiveram um atendimento fora do padrão ou irregular:

Regular, demora a vir a mesa (Francisco);

Regular, Caixa para pagamento desorganizado (Rafael);

Bom, A comanda é um pouco desorganizada (Patricia);

Ruim, porções irregulares, o mesmo prato servido em quantidades diferentes (Josenilton).

Importante ressaltar que, em sua totalidade, mais da metade dos clientes responderam a enquete relatando bom atendimento.

Tabela 3 - Qualidade do serviço de mesa segundo a clientela do Buraco da Catita. Natal, RN. $n=32$

\begin{tabular}{lcc}
\hline Variável & N & \% \\
\hline Serviço de Mesa & & \\
Ótimo e Bom & 21 & 65,6 \\
Regular & 8 & 25,0 \\
Ruim & 3 & 9,4 \\
Atendimento & & \\
Ótimo e Bom & 21 & 65,6 \\
Regular & 7 & 21,9 \\
Ruim & 4 & 12,5 \\
Total & 32 & 100,0 \\
\hline
\end{tabular}

Fonte: Pesquisa DETUR/UFRN, 2015.

Os resultados assemelham-se aos achados de Lima, Cunha e Moreira (2019). Os serviços prestados pelos restaurantes e bares reiteram a importância da gastronomia para o turismo, com a oferta de cardápios regionais e coquetéis, música ao vivo, recursos audiovisuais (Lima, Cunho, \& Moreira, 2019). Em Natal, a comensalidade urbana se restringe ao interior dos bares, demandando consumo mínimo para usufruir de mesas com pouca alternativa de lazer ao ar livre, até mesmo à beira mar.

A partir da literatura, conclui-se que o bar desempenha o papel de espaço disponível para o lazer e como espaço de liberdade que difere da rotina cotidiana. Ainda, a partir da 
literatura, é possível concluir que o lazer através da comensalidade favorece o respeito a todos os povos e culturas, além de fortalecer a tolerância ativa para se lidar com as diversidades no contexto do Turismo e da Hospitalidade, concluiu Lima, Cunha e Moreira (2019).

\section{CONSIDERAÇÕES FINAIS}

Embora o bairro da Ribeira concentre grande parte do potencial para desenvolver o turismo histórico-cultural em Natal, o bairro apresenta baixa frequência turística. O perfil de público do Buraco da Catita caracteriza-se pela presença de adultos, do sexo masculino e moradores locais. Inicialmente há uma prevalência de participação do público masculino em atividades de lazer e turísticas em Bar e Botecos, conforme confrontação de dados com outra pesquisa realizada no bairro da Redinha em Natal. Tal achado é importante, e requer pesquisa direcionada a esse aspecto, pois aponta para uma diferenciação e ocupação dos espaços de lazer a partir do gênero.

A partir da pesquisa realizada, constatou-se que o Buraco da Catita apresenta-se com grande potencial turístico devido aos três elementos que fundamentam a cultura, que é a gastronomia, a música e a edificação histórica.

A gastronomia local é um dos grandes diferenciais para atrair o público, demonstrando verdadeiro potencial para atividades turísticas com a valorização da cozinha regional. A comensalidade e a música reiteram a hospitalidade aos residentes que frequentam o bar. Para turistas e visitantes o espaço revela artistas locais e oferece petiscos típicos da cozinha potiguar.

Vislumbrou-se também que o espaço Buraco da Catita incentiva à identificação histórica do bairro da Ribeira em Natal/RN, contribuindo para fomentar atividades que envolvam o turismo cultural. Há ainda, o enlace da atividade turística, gastronomia e musicalidade, com artistas da região, que fortalece a identidade do local e faz do bar o espaço ideal para turistas ao garantir uma experiência completa com a cultura local.

Para fomentar o turismo cultural faz-se necessário considerar aspectos que envolvam a divulgação, infraestrutura de acessibilidade e segurança, evidenciando as edificações históricas. Nesse contexto, a comensalidade é essencial para estabelecer a experiência turística e como estratégia de aproximação entre moradores e turistas. 


\section{REFERÊNCIAS}

Andrade, M. O. (2000). Cultura e tradição nordestina: ensaios de história cultural e intelectual. João Pessoa: Manufatura.

Barreto, R. L. G., \& Senra, A. V. (2001). A Gastronomia e o Turismo. In: Ansarah, M. G. R. Turismo Como Aprender, como ensinar. (2a. ed.). São Paulo: Editora SENAC.

Barreto, M. (2006). Turismo, cultura e sociedade. Caxias do Sul, RS: Educs.

Bentivegna, F. J. (2002). Fatores de impacto no sucesso do marketing boca a boca online. Revista de Administração de Empresas, 42(1), 79-87.

Bezerra, W., \& Moreira, S. A. (2017). Gastronomia e turismo na fazenda Bom Jardim Goianinha/RN. Revista Turismo \& Desenvolvimento - RTD, 16(2), 27-42.

Bosi, E. (2004). O tempo vivo da memória: ensaios de psicologia social. São Paulo: Ateliê Editorial.

Brasil. (1937). Decreto-lei no 25, de 30 de novembro de 1937. Organiza a proteção do patrimônio histórico e artístico nacional. Rio de Janeiro.

Brasil. Ministério do Turismo. (2010). Turismo Cultural: orientações básicas. Ministério do Turismo, Secretaria Nacional de Políticas de Turismo, Departamento de Estruturação, Articulação e Ordenamento Turístico, Coordenação Geral de Segmentação. (3a. ed.) Brasília, Ministério do Turismo.

Cascudo, L. C. (1999). História da Cidade do Natal. (3a. ed.). Natal, RN: IHGRN.

Cascudo, L. C. (2004). História da alimentação no Brasil. (3a. ed.). São Paulo: Global.

Castro, F. M. M., \& Santos, J. G. M. (2012). A cultura gastronômica como atrativo turístico: relato de uma experiência de pesquisa nos Restaurantes de Aracaju/SE. Revista Hospitalidade, IX(2), 155-174.

Castelli, G. (2010). Hospitalidade - A inovação na gestão das organizações prestadoras de serviços. São Paulo: Editora Saraiva.

Contreras-Hernández, J. C. (2005). Patrimônio e Globalização: o caso das culturas alimentares. In Canesqui, A. M., \& Garcia, R. W. (Org.). Antropologia e nutrição: um diálogo possível. Rio de Janeiro: Editora FIOCRUZ.

Cuche, D. (2002). O Conceito de Cultura nas Ciências Sociais. Tradução de Viviane Ribeiro. (2a. ed.) Bauru, SP: EDUSC.

Defert, P. (1987). Tourisme et gastronomie. Revue de tourism - Revista da association international d' Experts Scientifiques du Tourisme (AIEST), St. Gallen, Suice, 42(3), 7-8.

Fagliari, G. S. (2005). Turismo e Alimentação - Análises Introdutórias. (1a. ed.). São Paulo: Editora Roca.

Franco, A. (2001). Caçador a Gourmet: uma história da gastronomia. São Paulo: Ed. SENAC Nacional. 
Fernandes, A. (2015). Ribeira velha de guerra. Um relato sobre as origens e o desenvolvimento econômico, social e cultural do bairro mais importante de Natal. Natal, Departamento Estadual de Imprensa/DEI, Nós do RN.

Gennep, A. V. (1977). Os ritos de passagem. Trad. Mariano Ferreira. Apresentação Roberto da Matta. Petrópolis: Vozes.

Gomes, C. L. (Org.). (2004). Dicionário crítico do lazer. Belo Horizonte: Autêntica Editora.

Grinover, L. (2007). Hospitalidade: um tema a ser reestudado e pesquisado. In: Dias, C. M. M. Hospitalidade: reflexões e perspectivas. Baruer: Manole.

Instituto do Patrimônio Histórico e Artístico Nacional - IPHAN. (2014) Instrumentos de Proteção. Brasilia: Ministério do Turismo.

Lima, M. M., Dalcin, J. F., \& Barros, Y. E. M. (2016). Ginga com tapioca: gastronomia do mercado da Redinha como atrativo turístico. Revista de Turismo Contemporâneo, 4(1), 45-66.

Lima, K. R. S., Cunhas, S. M., \& Moreira, S. A. (2019). Comensalidade em bares como opção de lazer entre jovens da Zona Norte de Natal/RN. Revista Cenário: Revista Interdisciplinar em Turismo e Território, 7(13), 103-116.

Lima, M. M., Dalcin, J. F., \& Barros, Y. E. M. (2012). Do esplendor do Cabaré de Maria Boa ao ostracismo do Beco da Quarentena (1942-1950). Anais da ANPUH/RN. Caicó, Rio Grande do Norte, Brasil.

Meksenas, P. (2002). Pesquisa Social e Ação Pedagógica: conceitos, métodos e práticas. São Paulo: Ed. Loyola.

Miranda, D. S., \& Cornelli, G. (2004). Cultura e Alimentação. (2a. ed.). São Paulo: SESC SP.

Miranda, L. (2008). A Importância do Marketing Aplicado ao Turismo para o

Desenvolvimento de um Município. Catas Altas: Um Estudo De Caso. Portal do Marketing,

Belo Horizonte, MG.

Montanari, M. (2008). Comida como cultura. São Paulo: Senac.

Moreira, S. A. (2010). Alimentação e comensalidade: aspectos históricos e antropológicos. Ciência e Cultura, 62(4), 23-26.

Morin, E. (1997). O Método 4: As idéias, habitat, vida, costumes, organização. Porto Alegre: Sulina.

Muneiro, L. C., \& Freire, L. (2012). Natal: copa, história e sabores: o olhar dos acadêmicos do curso de comunicação social da UFRN. Natal: EDUFRN.

Nascimento, G. (2015). Ribeira: um estudo geohistórico do bairro da zona leste de NatalRN. Geoconexões, 2(1), 27-37.

Polàcek, M. (1986). Eating habits of czescholosvack population and gastronomy as a tourism motivation. Revue de tourism. St. Gallen, Suice, 41(4), 22-25.

Organização das Nações Unidas para a Educação, a Ciência e a Cultura - UNESCO (2006). Convenção para a salvaguarda do patrimônio cultural imaterial. Documento originalmente publicado pela UNESCO sobre o título Convention for the safe guarding of the Intangible 
Cultural Heritage, Paris, 17 October 2003. Brasília, Tradução feita pelo Ministério das Relações Exteriores.

Secretaria Do Meio Ambiente e do Urbanismo - SEMURB. (2007). Conheça Melhor o seu Bairro 2007 - Ribeira. Natal, RN, Prefeitura Municipal do Natal, 7-8.

Silva, V. B. (2013). Gestão da qualidade dos serviços prestados em bares e restaurantes na praia da redinha (Natal-RN). 63 f. Trabalho de Conclusão de Curso, Universidade Federal do Rio Grande do Norte, Natal, RN, Brasil.

Schiffman, L., \& Kanuk, L. (1995). Consumer behavior. New Jersey: Prentice Hall.

Schlüter, R. G. (2003). Gastronomia e Turismo. São Paulo: Editora Aleph.

Tavares, A. G., Dantas, J. P., \& Nóbrega, W. R. M. (2014). Patrimônio cultural e turismo: a cachaça como instrumento de valorização e desenvolvimento. Anais XI Seminário da Associação Nacional Pesquisa e Pós-Graduação em Turismo. Universidade Federal do Cerará, Ceará, Brasil.

\section{FORMATO PARA CITAÇÃO DESTE ARTIGO}

MOREIRA, S. A., DANTAS, A. A. G., OliveiRA, C. K. A., CAVALCANTE, M. B., \& CUNHA, S. M. (2021). Hospitalidade no Buraco da Catita: música e comensalidade como atrativos turísticos em Natal/RN, Brasil. Revista de Turismo Contemporâneo, 9(1), 148-171. https://doi.org/10.21680/2357-8211.2021v9n1ID19914 